\title{
Mine waste cover system design - considerations for cold regions
}

\author{
B. Dobchuk O'Kane Consultants Inc., Canada \\ M. Nahir Aboriginal Affairs and Northern Development Canada, Canada
}

M.A. O'Kane O'Kane Consultants Inc., Canada

B. Ayres O'Kane Consultants Inc., Canada

\begin{abstract}
The contaminated sites program of Aboriginal Affairs and Northern Development Canada (AANDC) is responsible for closure of contaminated sites on Crown land throughout the Canadian north. A significant percentage of the closure liabilities faced by AANDC are associated with abandoned mines. Of these minerelated liabilities, many involve the need to construct earthen cover systems over potentially reactive tailings and waste rock in cold regions. AANDC will be implementing cover systems at sites in the very near future and therefore require that critical questions in regards to cold regions cover systems be addressed: i) what are the key processes that will affect performance of different types of cover systems within a cold regions context; ii) how should the design process incorporate these issues; and iii) what are the risks to long-term performance as a result of these cold regions phenomena. This paper outlines the technical guidance approach for cover systems in cold regions that has been developed by AANDC with the assistance of a Technical Advisory Group (TAG).

Extreme climatic conditions in cold regions result in the ground surface reacting in ways not experienced in warmer regions of the world. These terrain features are caused by frost action processes. Frost action refers to soil behaviours that are the result of freezing and thawing of water within the soil matrix. Key points from the guidance document are presented. Cover system design philosophy as it relates to cold regions is discussed including utilising attributes of cold regions in design. Designing for sustainability highlights the importance of final landform design and key failure mechanisms for covers in cold regions: thermokarst, solifluction, and glaciation of surface water management systems. An emphasis is placed on robust landform design as well as the importance of risk assessment to evaluate final cover design. A generic case study is presented to provide an example of a cold regions cover design and the results of a risk assessment.
\end{abstract}

\section{$1 \quad$ Introduction}

The contaminated sites program of Aboriginal Affairs and Northern Development Canada (AANDC) is responsible for remediation of contaminated sites on government-owned land throughout the Canadian North. A significant percentage of the remediation liabilities faced by AANDC are associated with abandoned mines, of which many involve the need to construct soil (earthen) covers over reactive tailings and waste rock. AANDC requires additional information on key physical, chemical, and biological processes that affect long-term risk to these cover systems. The appropriate design and long-term effectiveness of earthen covers in cold regions is therefore of central importance to AANDC, as well as to local and regional stakeholders.

The Mine Environment Neutral Drainage (MEND) program recently completed a two-phase review of soil covers on mine wastes in cold regions (MEND 1.61.5a, 2009; MEND 1.61.5b, 2010). Several dozen cold regions processes were identified as potentially significant for soil covers. The most widespread are ground freezing and ground ice formation, ground thawing and associated settlement, and freeze-thaw cycling. Combinations of these processes with specific soil or hydrologic conditions can change soil properties, such as compaction and permeability, or lead to the development of macroscopic features, such as solifluction, cracking, mounding or hummocks, or mudboils. These effects can develop slowly enough that they may not 
be obvious in current observations of soil covers, but quickly enough that they might have significant effects over a cover's design life.

Following the Phase 1 and 2 reviews, AANDC's objective was to lead the development of a guidance document for covers in cold regions. The purpose of the guidance document is to not only outline the current state-of-knowledge of cover design in cold regions but also the expectations of AANDC on how a cover design process should be conducted. In particular, AANDC requires that critical questions in regards to cold region cover systems be addressed: i) what are the key processes that will affect performance of different types of cover systems within a cold regions context; ii) how should the design process incorporate these issues; and iii) what are the risks to long-term performance as a result of these cold regions phenomena. The present paper describes the cover design philosophy for cold regions, discusses key failure modes in cold regions, and briefly introduces a case study with a risk assessment. These topics are part of the technical guidance document.

\section{$2 \quad$ Key attributes of cold regions}

In the context of mine waste covers, an appropriate definition of cold regions would include any area where there is a regular occurrence of ground frost sufficient to affect cover performance. Ground frost penetration is a function of many factors such as soil mineral and textural composition, snow cover, and vegetation. To generalise, most regions where ground frost affects cover performance are areas with significant seasonal frost or permafrost. The majority of permafrost land exists in the Northern Hemisphere (Figure 1). In the Southern Hemisphere, alpine permafrost is found in the high-altitude Patagonia region of South America and New Zealand's Southern Alps and seasonal frost is found in some areas of South America. In Antarctica, only about $0.3 \%$ of the continent's total area is bare ground, but all of it is permafrost.

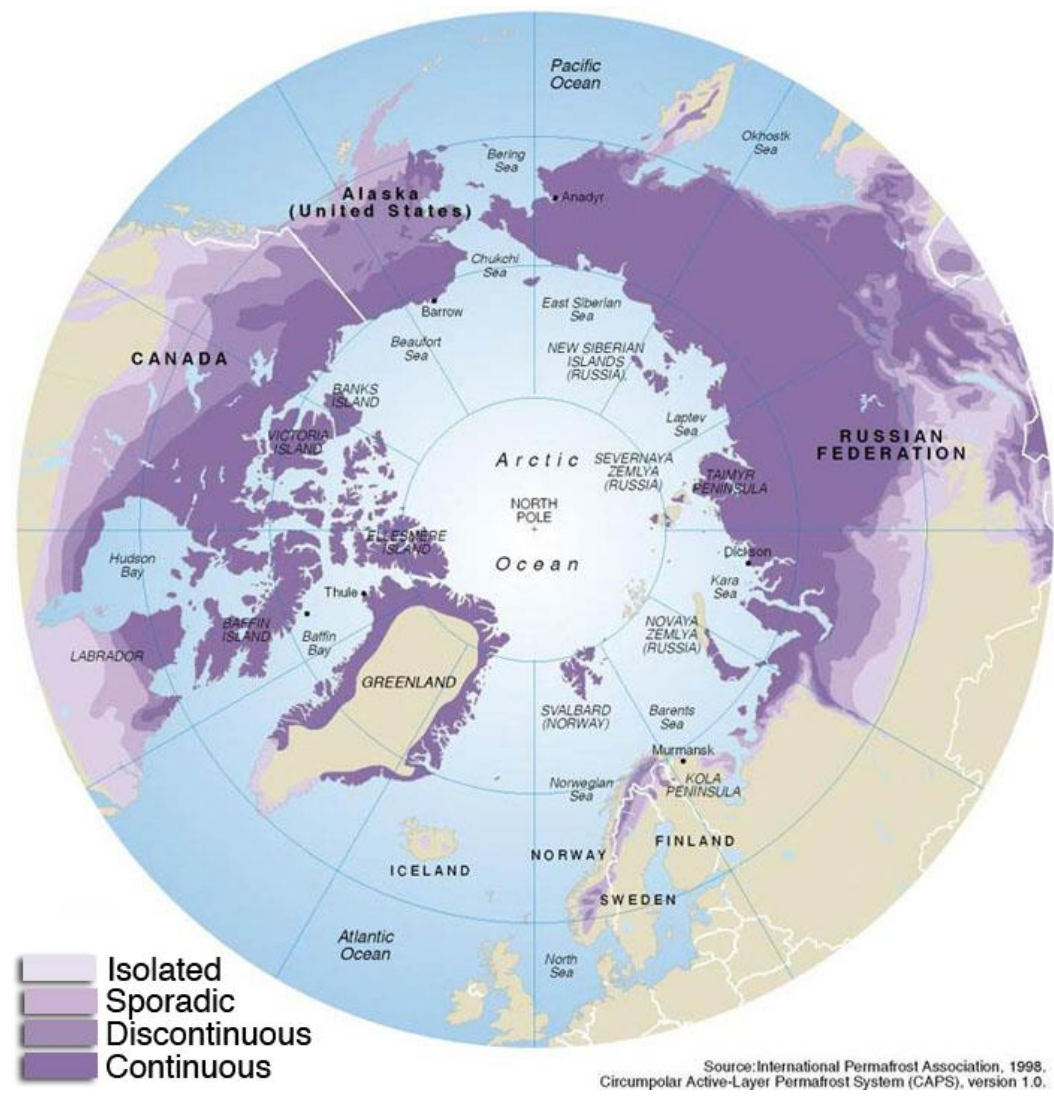

Figure 1 Northern hemisphere permafrost regions

Permafrost exists in either a continuous or discontinuous pattern. Discontinuous permafrost is the state of permanent ground freezing that occurs only in some scattered areas beneath the surface whereas 
continuous permafrost is defined by the presence of permanent ground freezing throughout the subsurface in all areas (Andersland and Ladanyi, 2004). In discontinuous permafrost zones, factors such as slope aspect, ground cover, and soil conditions affect whether or not a particular area will have permafrost or not. Permanently frozen ground in the discontinuous zone can vary widely, from depths of a few centimetres to depths exceeding $100 \mathrm{~m}$. Permanently frozen ground in the continuous zone can exist to a depth of more than a $\mathrm{km}$ and requires an annual freezing index of approximately 3,900 degree-days- ${ }^{\circ} \mathrm{C}$ to be sustained (Andersland and Ladanyi, 2004).

Cold regions typically experience extreme climate, the most obvious of which is prolonged cold air temperatures. In warmer regions, the importance of climate relates predominantly to moisture transfer between the atmosphere and the ground. In cold regions, the importance of climate extends to heat transfer between the atmosphere and the ground. Other cold regions climate factors affecting cover performance include snow cover, surface radiation, convective heat flow, evaporation, and condensation.

Extreme cold climatic conditions result in the ground surface reacting in ways not experienced in other regions of the world. Washburn (1973) stated that where a climate is sufficiently cold it will leave physical evidence of its influence. Common terrain features associated with cold regions include ice wedges, pingos and palsas, thermokarst, patterned ground, boulder fields/pavements, mounds and/or hummocks, mudboils, circles and diapirs, and involutions. MEND 1.61.5a (2009) includes a description of each of the above terrain features. The significance of frozen ground phenomena for cold regions covers will depend on the time scales under consideration. Some of the features and processes that have the greatest impact on cover design in cold regions are illustrated in Figure 2.

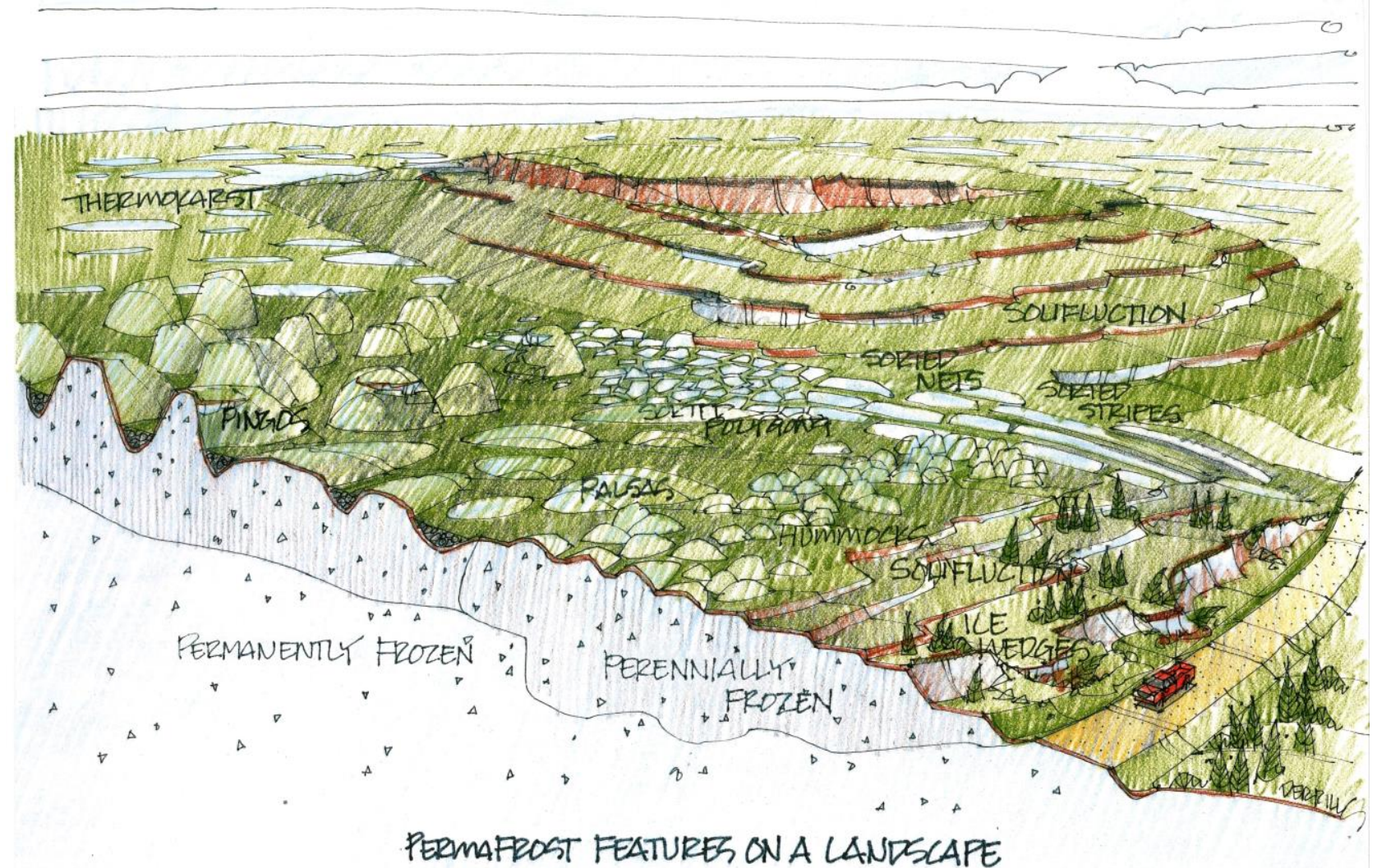

Figure 2 Cold regions processes affecting cover performance in cold regions 


\section{Cover design philosophy for cold regions}

\subsection{Cover design objectives}

Several factors influence and often dictate the design objectives of a cover system. The key factors for covers in a cold region include:

- surface energy balance

- surface water balance

- geochemical and geotechnical characteristics of the waste material

- hydrogeological setting of the waste storage facility.

The ground surface undergoes constant exchanges of mass and energy. In cover design, mass fluxes are largely water and vapour fluxes and are commonly evaluated using a water balance. In cover design for warmer climates, energy balances are usually only considered pertaining to movement of water vapour through the cover profile. However, for colder climates, energy balances are of greater importance to estimate ground freezing and thawing. The depths of ground freezing and thawing strongly influence the hydrological processes that occur, such as infiltration and redistribution of meltwater (Zhang et al., 2008).

Yamazaki et al. (1998) reported that the daily frost depth in the ground depends much more on the temperature profile inside a snow cover than on soil water content (at least when the volumetric water content was more than 0.1 ) or on vegetation. Solar radiation, thermal radiation, sensible heat flux, latent heat flux including phase change, soil heat flux, and advection are key processes for energy exchange between soil covers (land) and atmosphere. These factors vary temporally and spatially, which leads to temporal and spatial variability of a surface energy balance, and hence cover design objectives, in cold regions.

The surface water balance of a soil cover in all climates is associated with precipitation, runoff, evapotranspiration, and infiltration. Surface water balance evaluation is crucial for soil cover design because maintaining low infiltration rates can result in low contaminant loading to the environmental receptors. Cold regions generally experience seasonal precipitation with large snowfall in winters. Snowmelt in spring and/or summer may result in high water infiltration into the underlying wastes; therefore, cover design in cold regions should consider surface water balance for extreme climates.

The geochemical and geotechnical characteristics of the waste material could have significant influence on cover design objectives. For example, controlling contaminant release and provision of a growth medium may be the cover design objectives for a reactive waste rock pile while providing a growth medium could be the main objective for non-reactive tailing such as oil sands tailings.

The hydrogeological setting of the waste storage facility provides pathways for contaminants released from the waste material to the final environmental receptors. A relatively sealed hydrogeological setting could reduce the risk of the contaminant moving to the environmental receptors, thus benefiting the cover design and design objective.

The objectives of a cover system may vary from site to site but generally include:

1. Dust and/or erosion control.

2. Chemical stabilisation of mine waste (through control of oxygen or water ingress).

3. Contaminant release control (through control of infiltration).

4. Provision of a growth medium for establishment of sustainable vegetation.

Dust and erosion are typically minimised through placement of a material layer suitable for growth of vegetation to stabilise the soil. In cold regions, vegetation establishment is slow and may or may not be of sufficient density to control erosion in the long term. Mulch can be used to temporarily stabilise the 
surface; however, long-term erosion control in cold regions may require alternative controls such as placement of gravel to resist wind erosion and coarse rock riprap to resist water erosion.

The principal mechanism used to inhibit oxygen ingress is to utilise the low rate of oxygen diffusion through water. Cold regions processes and material availability reduce the ability to design a cover based on the development of tension-saturated conditions within a cover layer. Water covers in cold regions were outside the scope of the technical guidance document.

Limiting net infiltration of water into the waste in cold region covers follows most of the same guidelines as in warmer climates. The processes of creating a low hydraulic conductivity layer and/or utilising the storeand-release concept are typically considered. In cold regions, the limitations on these designs are material availability and processes affecting barrier layer integrity. A method of limiting infiltration can be taken advantage of in cold climates where the waste material can be frozen into the permafrost. At freezing temperatures, most of the soil water changes to ice and subsequently has a lower hydraulic conductivity. The applicability of this method is a function of the local climate.

Establishment of vegetation is generally more challenging on reclaimed sites in cold climates than in warmer regions, as short frost-free periods restrict the window for revegetation activities, the rate of vegetation establishment, and the range of plant species capable of colonising and persisting on a site. Primary challenges in cold region revegetation include: (1) limited species selection and availability, (2) slow rate of vegetation establishment, and (3) restricted or negligible availability of growth medium materials.

The cover design objectives should be site-specific. Site-specific objectives allow the needs of all the stakeholders to be included in the design process from the beginning. With clearly defined objectives, the cover designer has a more defined scope to proceed with the site and material characterisation and the development of the conceptual cover designs. The cover objectives may need to be revised based on field and performance information.

\subsection{Utilising attributes of cold regions}

Historically, many cold region covers have been designed based on experience and technologies developed for warmer climates. It is then hoped that the cover design will not fail over time due to differences in the climatic and geologic setting. Where possible, covers should be designed to take advantage of the climatic and geologic setting inherent to cold regions. Key attributes of cold regions pertinent to the design of a mine waste cover system include:

- low precipitation in the form of spring snow-melt and summer storm events

- high actual evapotranspiration (AET) rates compared to typical rainfall amounts during the summer months due to warm temperatures and long daylight hours

- prolonged, cooler temperatures during the winter months that can result in deeper frost penetration

- glacial deposits of relatively coarse-textured soils, which are less susceptible to frost action and may be suitable for a capillary break layer

- high runoff coefficient in the spring when only the upper surface has thawed

- surfaces are covered by snow and ice most of the year, thus limiting exposure.

Taking into account the above attributes, where possible, designers should consider incorporating the following elements into a cold region cover design:

1. Divert snow-melt waters to the greatest extent possible by incorporating topographic relief in the final landform design and/or incorporating a seasonally frozen layer.

2. Maximise AET rates during the summer months by establishing vigorous vegetation covers (where possible). This establishment and subsequent water removal can be enhanced by incorporating 
organics or fine-textured mineral materials, where available, in the upper cover profile to increase the amount of available soil water for plant and atmospheric demands.

3. Encourage deep freezing of the waste material where possible to minimise percolation of meteoric waters through the waste material.

4. Use compacted, coarse-textured materials to achieve relatively low hydraulic conductivity due to the negative effects of frost action on fine-textured materials such as compacted silt/clay or compacted sand-bentonite within the active zone.

5. In tailings covers (saturated waste), address the potential for post-cover construction deformation due to freezing of contaminated water.

6. If required, liners must be installed where they are not subject to freeze-thaw processes.

7. Consider the cost benefit of post-closure sustainability into upfront cover investment in relation to proposed design life.

\section{$4 \quad$ Designing for sustainability}

Ideally, closure of a mine waste storage facility should generate a 'walk-away' solution. However, as with all engineering, and in particular with mine waste management, elements of a closure plan are subject to failure and, consequently, have a fixed lifespan. To design a cover system to maximise longevity means incorporating an 'engineered' structure into the landscape in a way that is sustainable over the long term. The two most important disturbances associated with the closure of a mine site are those associated with water balance (hydrological disturbance) and energy balance (thermal disturbance). The mining activity, as well as the construction of the mine closure design, creates landforms that are no longer in equilibrium with the surrounding environment. This creates a state of both hydrological and thermal disequilibrium. The designer must address the implications that re-establishment of equilibrium conditions may have on the performance of closure landforms, a process which, in permafrost regions, may take hundreds of years.

The longevity of a cover design in cold regions is a function of site-specific physical, chemical, and biological processes that will alter as-built performance and determine long-term performance (see Figure 3). Some physical processes include erosion (water and wind), frost heave, frost degradation (thermokarst), slope instability, wet/dry cycles, freeze/thaw cycles, consolidation, extreme climate events, and brushfires. Chemical processes include osmotic consolidation, dispersion, dissolution, sorption, acidic hydrolysis (chemical weathering), oxidation, salinisation, and mineralogical consolidation. Biological processes include root penetration, burrowing animals, bioturbation, human intervention, bacteriological clogging, vegetation establishment, and physiology.

\subsection{Importance of final landform design}

Final landform design is an important consideration for designing cover systems for waste storage facilities located in cold regions. Poor surface water management and landform instability are common factors leading to failure of cover systems around the world (MEND 2.21.4, 2004). The primary reason for this is a design approach that attempts to build engineered structures to oppose natural processes rather than developing engineered systems based on natural analogues that integrate rapidly with the surrounding hydrologic and ecosystems following implementation (Ayres et al., 2006). Careful consideration must be given to the planned final landform for a waste storage facility to ensure that performance of a given cover system can be sustainable over the long term. A large challenge is the long timeframe of interest, in the order of hundreds to thousands of years. The changes that will occur during this period are difficult to predict and quantify, yet will affect the system.

Landform design is dependent on numerous factors, including climate, geology, soils, local hydrogeologic patterns, topography, and final land use (MEND 2.21.5, 2007). The final landform design (including the cover system) depends greatly on the mine closure objectives established by the stakeholders. Generally, 
the reclaimed landscape must be returned to a productive land use. Examples include wildlife habitat, traditional uses by aboriginal communities, and commercial forestry. Successful reclamation will not 'restore' a landscape but rather provide conditions for a landscape to 'develop' towards a capability equivalent to that existing prior to mining (MEND 2.21.5, 2007). The priorities of general landform design are to create a stable landform, and have the landform meet slope and shape criteria determined by the land-capability requirement. After these criteria are met, additional details can be incorporated, such as the cover system and drainage channels.

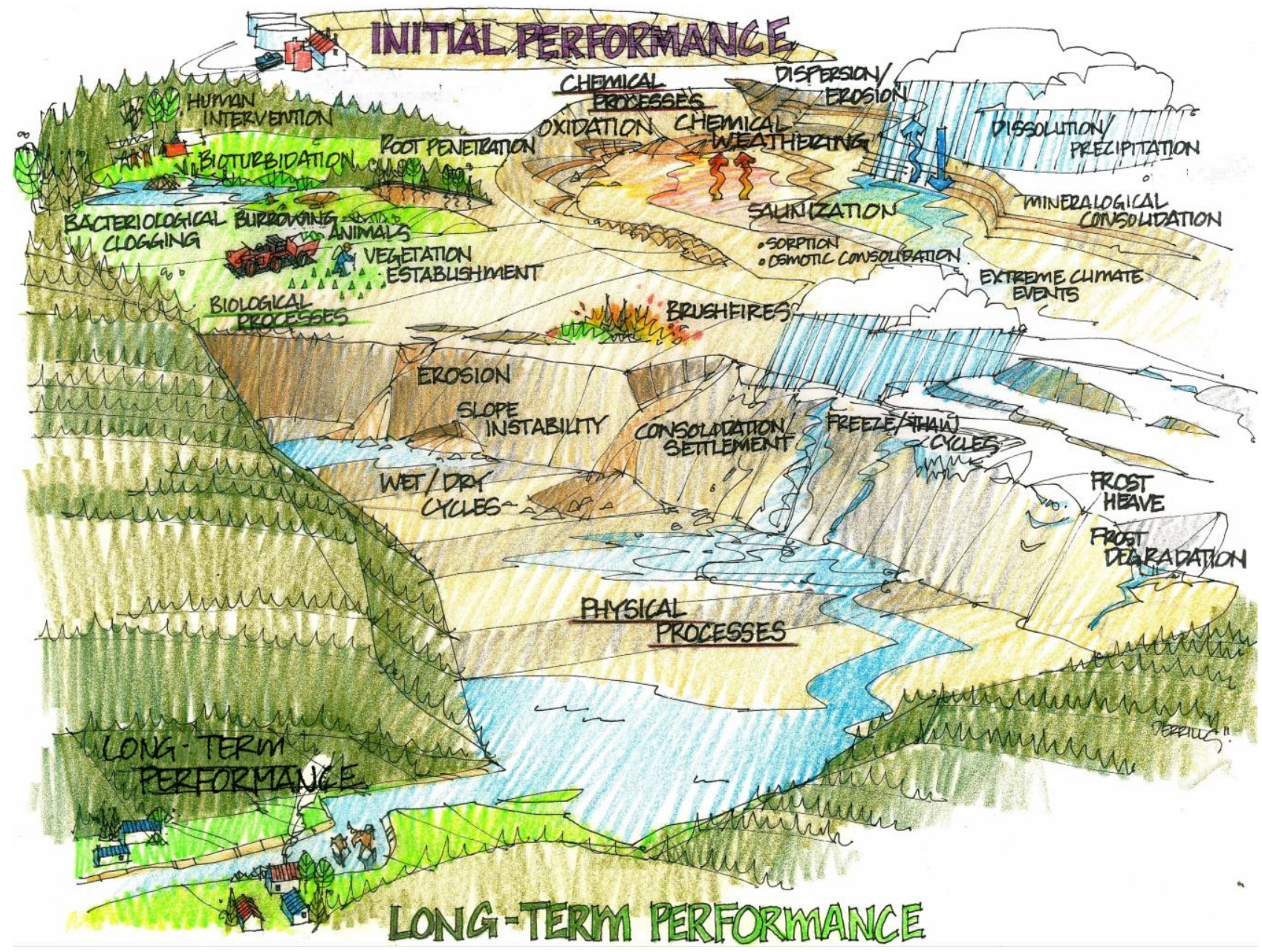

Figure 3 Conceptual illustration of processes affecting long-term performance of cover systems in cold regions

Often, the methods to achieve a stable landform in a cold regions climate have more complex consequences than in more temperate climates. For example, it would be ideal to limit snowpack development on a waste storage facility from an environmental loading and erosion perspective; however, this results in the cover profile being more susceptible to freeze/thaw cycling, which could have detrimental impacts on long-term performance. Increasing the thickness of snowpack through reduction of wind drifting will reduce the thickness, and thus construction cost, of a growth medium layer designed to prevent frost penetration into an underlying barrier layer. However, this creates a challenge in dealing with large spring melt runoff.

\subsection{Key failure mechanisms}

Of the potential failure mechanisms for cover systems in cold regions, three key failure mechanisms have been identified:

- shortened construction and vegetative timelines 
- entrapment of ice layers within deposit

- glaciation (icing) of surface water channels.

Due to the shortened growing season in cold regions and resultant effective construction season for earthworks, construction timelines need to be modified from what is typically performed in warmer climates. A shortened field season means less time to move earth or sub-cover material to accommodate the design of the cover system and impoundment as a whole. Winter construction must often be considered. Access to site to bring in specialised equipment or materials may only occur via winter roads in some regions, creating additional logistical challenges. In addition, the shortened field season correlates to a shorter period to promote vegetative growth, meaning erosion control measures will need to be maintained longer to prevent degradation of the cover and ensure adequate vegetative growth. The compressed timeline and logistical challenges in cold regions can result in higher than expected costs for labour, equipment, and materials, as well as short-term failure of erosion protection.

As tailings are placed in cold regions, a substantial risk exists to entrap ice layers. Due to expansive properties of frozen water, these entrapped frozen materials will provide a temporary increase to overall volume of the deposit. As these layers thaw over time, thaw consolidation will lead to differential settlement. If reclamation has occurred prior to final thaw settlement, failure of the reclaimed landform can result.

Traditionally, the most common soil cover materials utilised as mine waste cover systems have been wellgraded, finer textured soils used to create elevated zones of saturation to limit oxygen ingress. These conditions are likely to place these covers at risk from frost action under climatic conditions present in cold regions. Table 1 describes a number of sites in which frost action and a lack of appreciation for the potential detrimental effects of cold region phenomena have had an adverse effect on tailings storage facility performance.

Following cover placement, the landform design typically includes the construction of surface water management swales and channels as erosion control measures. One of the most common failure modes of cover systems in general, and for cover systems in cold regions in particular, is the failure of the surface water management system to safely convey runoff off the landform. A surface water management system will be successful if it manages to convey all the required surface water and does not suffer greatly from erosion, sedimentation, and turbidity. Surface water management systems must be robust, as any failure is visible to stakeholders. Even if the failure does not result in increased contaminant loading or other critical failures, the surface drainage system is visible and even small glimpses of erosion give the impression of poor design and management. In cold regions, care must be taken to consider spring snowmelt in conjunction with the design rainfall event, as well as glaciation of surface water conveyance channels.

Glaciation of surface water channels and ditches, particularly near the 'outlet' area of the landform, is a very common failure mechanism of cover systems in cold regions. Channels flow as designed during summer and are dry or fully frozen in the winter. However, in spring and fall, as temperatures fluctuate daily above and below freezing, glaciation of the channels may occur. In fall, moving water may freeze in layers, causing blockages that may give rise to flow diversion over the top of the channel, causing erosion of the cover material. In the spring, similar issues may be observed when slush, ice, and water mixtures flow in the channel or the channel may be blocked by snow drifts, causing flooding or flow diversion.

In cold regions, mitigation of these and many other failure modes can be accomplished through rigorous landform design, including modelling and prediction of thaw consolidation. Key factors are establishing adequate vegetation, proper grading of contours, berms, and swales, diversion ditches, and rock armouring (Norman et al., 1997). Reclamation of large waste storage facilities should include the construction of small catchment areas and wetlands upstream of final surface water discharge points when compatible. 


\section{Table 1 Summary of case studies describing failures due to cold region features}

\begin{tabular}{|c|c|}
\hline Failure Mechanism & Result of Failure (MEND 1.61.5a (2009)) \\
\hline $\begin{array}{l}\text { Permafrost } \\
\text { degradation } \\
\text { beneath reactive } \\
\text { waste due to heat } \\
\text { generation in } \\
\text { waste material }\end{array}$ & $\begin{array}{l}\text { - Subsidence of tailings dam crest (United Keno Hill Mine, YK). } \\
\text { - Movement of dump crest and repair requirements post closure (Brewery Creek } \\
\text { Mine, Dawson, YK). } \\
\text { - Increase in width of talik associated with creek that previously ran through } \\
\text { valley (Red Dog Mine, Alaska). }\end{array}$ \\
\hline & $\begin{array}{l}\text { - Thermokarst topography and differential settlement due to melting of entrained } \\
\text { ice (Colomac Mine, Faro Mine, YK). } \\
\text { - Reduction in volume available for deposition of tailings due to ice occupying } \\
\text { estimated tailings volume (Rabbit Lake Mine, SK). }\end{array}$ \\
\hline Convective cooling & $\begin{array}{l}\text { - Enhancement of other frozen ground processes which could contribute to } \\
\text { detrimental performance (anecdotal evidence at Key Lake Mine, SK). } \\
\text { - Cryocentration and explusion of tailings pore fluids is expected at Snap and } \\
\text { Diavik. }\end{array}$ \\
\hline $\begin{array}{l}\text { Migration of fines } \\
\text { through cover }\end{array}$ & $\begin{array}{l}\text { - Fine tailings covered with a shallow rock layer-boils containing fines formed on } \\
\text { surface after } 5 \text { years. Required new engineered cover } 10 \text { years following } \\
\text { deposition, but boils continued to form on surface. A second new cover was } \\
\text { placed following another } 10 \text { year cycle (Beaverlodge Mine, SK). It was later } \\
\text { determined the main cause was high pore pressures combined with freeze/thaw } \\
\text { cycles. } \\
\text { - } 0.3 \mathrm{~m} \text { silty clay overlain by } 0.3 \mathrm{~m} \text { crushed rock cover had boils form } 7 \text { years } \\
\text { following deposition, consisting of fine textured material being forced through } \\
\text { pore space in crushed rock (Discovery Mine, NWT). }\end{array}$ \\
\hline
\end{tabular}

\subsection{Climate change}

An additional consideration for the long-term sustainability of cover system performance in cold regions is reduction of permafrost associated with climate change, more specifically warming in northern latitudes. Melting of permafrost (i.e. becoming seasonally frozen rather than permafrost) has raised concern in the scientific community; in relation to cold region soil covers, permafrost offers several benefits for cover performance, which include impediment of vertical drainage, negatively affecting infiltration rates, and increasing levels of runoff (Carey and Woo, 2001). If permafrost and its associated benefits were to disappear, it is unlikely that the cover would fail. In this instance, failure is an iterative process and should be viewed as a probability curve that highlights the probability of the cover system being able to 'supply' the appropriate conditions to support the desired vegetation and achieve cover performance objectives (Elshorbagy and Barbour, 2006). A warmer climate and associated permafrost melt would most likely result in conditions more suitable for a larger variety of vegetation and/or vegetation that transpire water at a higher rate (taller shrubs and trees). As such, increased soil moisture and available water holding capacity (AWHC) due to permafrost melt could shift the site capability to a wetter system, where another community could occupy the site over another operative edatopic range.

\section{Case study - cover design risk assessment}

A key component of the cover design methodology outlined in the guidance document is a Failure Modes and Effects Analysis (FMEA). The FMEA is a risk analysis that highlights potential failure modes and can be completed at an early stage in the design process. Cover systems with high potential failure rates can be omitted from consideration and/or modifications can be made to cover system designs to mitigate these 
failure modes. For example, if long-term maintenance is not desired in the final cover design, the FMEA can show long-term maintenance requirements as a failure mode, highlighting which cover designs result in long-term maintenance.

A case study is presented that is generically representative of a climatic condition encountered in a cold region (discontinuous/seasonal permafrost). The case study is presented to demonstrate the application of the FMEA process to cover system design in cold regions. Though the case study is based on an actual site and dataset, it has been simplified into an idealised case study to highlight the FMEA process rather than the outcomes. The outcomes of an FMEA from one site cannot be applied directly to another site; each site not only has unique climate and materials, but unique stakeholder needs that change the relative consequences of failure.

Background for the case study is presented, followed by the cover system design performance criteria and a description of the cover system design and materials. The results of the FMEA are summarised in tabular format, with key discussion points included that provide examples of typical interpretations of the FMEA results.

\subsection{Background}

The case study site comprises waste rock dumps (WRDs) at an abandoned zinc and lead mine in the discontinuous/seasonal permafrost zone of northern Canada. Over $32 \mathrm{Mt}$ of sulphidic waste rock capable of producing acidic drainage exist at the site. The WRDs possess both north- and south-facing slopes at approximately $3 \mathrm{H}: 1 \mathrm{~V}$ gradients. The surrounding landforms include morainal till veneers and till blankets along with glaciofluvial and glaciolacustrine deposits. The WRDs are composed of coarse waste rock that is free draining; therefore, the potential exists for convective gas transport.

The site is semi-arid and has an annual average air temperature of $-2^{\circ} \mathrm{C}$, with daily averages ranging from -20 to $15^{\circ} \mathrm{C}$. Mean annual precipitation at the site is $300 \mathrm{~mm}$ with approximately one-third falling as snow. Actual evapotranspiration varies from $75 \mathrm{~mm} / \mathrm{yr}$ for a north-facing slope to $200 \mathrm{~mm} / \mathrm{yr}$ for areas with large amounts of available moisture and incoming radiation. Spring thaw takes an average of 15 days to thaw to a depth of about $0.75 \mathrm{~m}$ and an additional 20 days to thaw to a depth of approximately $2 \mathrm{~m}$.

Infiltration through the WRD is currently leading to groundwater contamination in the area, which results in surface water contamination. The pit area was flooded and the waste rock was deposited in a series of dumps surrounding the pit. A creek initially flowed directly over the pit area but the water is currently diverted around the pit. Studies have shown that it is not stable to maintain this diversion over the long term.

Cover material suitable for use as a low-permeability cover layer is available in the surrounding area, as is granular cover material. Coarse rock fill is not readily available and must be obtained by processing granular deposits or geochemically suitable waste rock, or by quarrying bedrock. A limited volume of organic soil is available, but requires significant effort to develop road access and would require new disturbance.

\subsection{Cover system performance criteria and design}

The case study cover system design is based on its ability to achieve certain levels of performance. Vegetation establishment is an important factor over the long term as forests will increase ET rates, decrease freezing depth, and create wildlife habitat. The cover system design performance criteria for the WRDs are low net percolation (5-15\% of precipitation), dust control, erosion control, geotechnical stability, vegetation establishment, and to control/reduce convective gas transport.

To meet the performance criteria, the cover system design chosen for closure of the WRDs is $0.5 \mathrm{~m}$ of compacted till placed directly on the prepared waste rock surface, overlain by a minimum of $0.5 \mathrm{~m}$ of noncompacted till (Figure 4). The till cover material has a tendency to become dense and hard packed following placement, which can result in rill and sheet erosion, and presents challenges for establishing vegetation. The surface of the cover system becomes slick and is often non-trafficable when wet. 


\subsection{FMEA results}

A failure modes and effects analysis (FMEA) is a methodology for assessment of associated risks, which are a combination of likelihood and consequences of failure (described in detail by Robertson and Shaw (2006)). In the context of cold regions cover design, failure is defined as the cover system no longer meeting the design expectation and/or criteria. Some failures will be repairable and others will require a critical assessment of whether a new or reconstructed cover system is required. An FMEA's value and effectiveness depends on having experts with the appropriate knowledge and experience participate in the evaluation during which failure modes are identified, risks estimated, and appropriate mitigation measures proposed. Therefore, the team must include representatives who understand the geotechnique, hydrology, environmental impacts, and regulatory requirements applicable to the engineered and natural systems and their surroundings, as well as the past history of the mine.

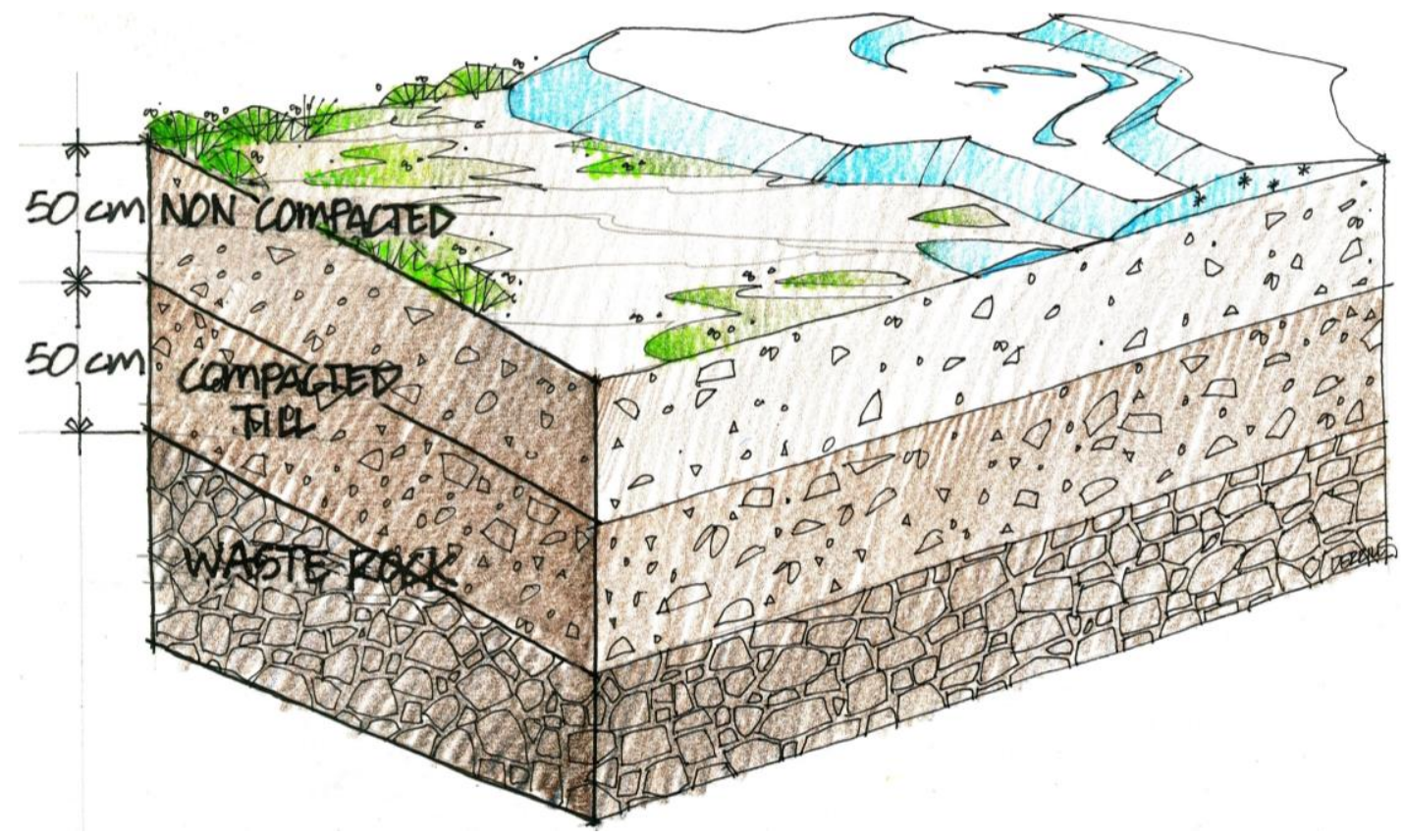

Figure 4 Case study cover system design

The first step in an FMEA is for the various evaluators to determine a list of potential failure modes for the site and identify the effects and pathways for each. The second step is to determine the consequences of failure. Failure modes may have physical, biological, health and safety, and cost consequences, among others. The estimate of consequences is based on a professional judgement of the anticipated impact of that failure. The impact encompasses both the concepts of likelihood of failure, or 'expected' frequency of failures, and 'severity of the expected consequences' if such events were to occur. The level of confidence the evaluators have with their ratings will vary based on the knowns and unknowns of each site and failure mechanism.

Once the severity of the consequences, the likelihood of the failure occurring, and the level of confidence in the estimate is determined, each failure mode then falls into a risk matrix, shown in Figure 5. The 'High' and 'Critical' risk levels should be viewed as unacceptable and steps taken to reduce these risk. The 'Moderate' and 'Moderately High' levels are acceptable if they are 'As Low as Reasonably Practical' (ALARP). For a risk to be ALARP it must be possible to demonstrate that the cost involved in reducing the risk further would be grossly disproportionate to the benefit gained. The 'Low' risk designation is broadly acceptable.

The failure modes identified for the case study and the resulting risk rating from the FMEA are listed in Table 2. The results of the FMEA showed five failure modes that fell under the critical risk category, three high risk failure modes, and five moderately high risk failure modes. Both the critical and high risk categories are considered an intolerable risk, whereas the moderately high risk categories are considered risks that should minimised to As Low As Reasonably Practical (ALARP). 


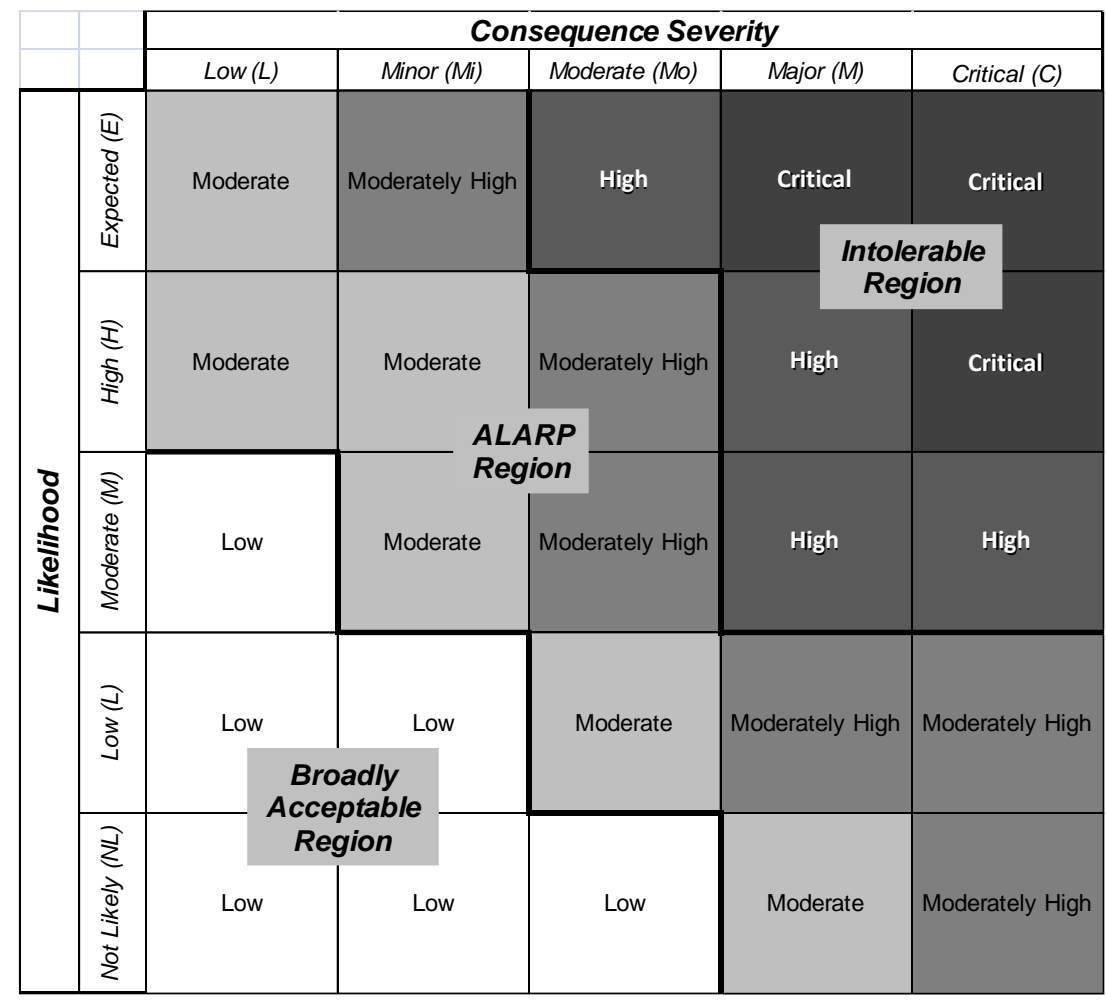

\section{Figure 5 Risk matrix for FMEA}

The first critical failure mode was 'erosion to the extent that spillway performance is degraded and ponding and bypass occurs'. This failure mode would result in erosion extending back up into or onto the cover system and would result in a breach of the cover system. The cover system breach would result in loss of isolation of waste rock and transport of waste materials into the environment. This failure mode had critical severity in almost all consequence categories (environmental impact, legal and other obligations, consequence costs, community/media/reputation, and human health and safety consequences) and, combined with a high likelihood of occurrence (10-50\%), this failure mode became a critical risk failure mode. Mitigation recommendations for this failure mode are:

- construct erosion resistant channels leading into the spillway

- observe/measure cover performance under site climatic conditions

- inspect cover following storm events

- perform routine maintenance to repair rills and gullies.

From a design perspective, this failure mode could be mitigated by increasing the thickness of cover (growth medium), increasing design storm event criteria, evaluating if vegetation is capable of controlling erosion in the long-term, including surface erosion control measures (e.g. rock mulch) to control erosion until vegetation is established, and re-designing the landform and/or surface water management system. To re-design the landform and/or surface water management system, greater understanding would be required on the surface water flow patterns, the requirements of storm water channels, and potential landform evolution. 


\section{Table 2 Failure mode and effects analysis results for case study}

\begin{tabular}{|c|c|c|}
\hline ID & Failure Mode Description & Risk \\
\hline 1 & Erosion due to rainfall and snowmelt to the extent that cover profile is breached & high \\
\hline 2 & $\begin{array}{l}\text { Erosion due to rainfall and snowmelt to the extent that cover performance does not meet } \\
\text { design criteria }\end{array}$ & moderately high \\
\hline 3 & Erosion due to extreme event to the extent that the cover profile is breached & moderately high \\
\hline 4 & $\begin{array}{l}\text { Erosion to the extent that spillway performance is degraded and ponding and bypass } \\
\text { occurs }\end{array}$ & critical \\
\hline 5 & Freeze/thaw, wet/dry settlement, hummocks leading to cracking & critical \\
\hline 6 & Blockage of surface water drainage swales and/or channels due to sedimentation & moderate \\
\hline 7 & Blockage of surface water drainage swales and/or channels due to vegetation & moderate \\
\hline 8 & Blockage of surface water drainage swales and/or channels due to snow/ice & moderately high \\
\hline 9 & $\begin{array}{l}\text { Alteration of surface water drainage swales and/or channels due to disruption (frost heave, } \\
\text { settlement, including thermokarsts, etc.) }\end{array}$ & low \\
\hline 10 & Limitations in cover system constructability & low \\
\hline 11 & $\begin{array}{l}\text { Inappropriate/incorrect quality-assurance program for construction conditions and } \\
\text { inadequate and/or inexperienced quality control during construction }\end{array}$ & low \\
\hline 12 & Fire & moderate \\
\hline 13 & $\begin{array}{l}\text { Cover detachment, slippage, sloughing, due to thaw-induced pore-water pressures and } \\
\text { weakening at interfaces, and piping (assume underlying structure is stable) }\end{array}$ & moderate \\
\hline 14 & $\begin{array}{l}\text { Reduction in geotechnical stability due to cold regions phenomena such as ice lenses or } \\
\text { water layers }\end{array}$ & low \\
\hline 15 & $\begin{array}{l}\text { Consolidation/settlement/hummocks causing ponding as a result of chemical weathering } \\
\text { of waste rock and loss of shear strength }\end{array}$ & moderately high \\
\hline 16 & Material mixing due to cold regions phenomena such as mudboils and cryoturbation & low \\
\hline 17 & $\begin{array}{l}\text { Surface disturbances due to cold regions phenomena such as solifluction, boulder } \\
\text { movement, and frost mounding/hummock formation }\end{array}$ & moderate \\
\hline 18 & $\begin{array}{l}\text { Change in active layer depth due to climate change causing degradation of cover } \\
\text { performance }\end{array}$ & low \\
\hline 19 & $\begin{array}{l}\text { Dispersion/cementing/crusting (or clay sizes causing clogging of surface pores) of cover } \\
\text { material leading to a change in cover performance }\end{array}$ & moderately high \\
\hline 20 & Burrowing animals & low \\
\hline 21 & Vegetation effects (root penetration, blow down, etc.) & critical \\
\hline 22 & $\begin{array}{l}\text { Poor vegetation establishment due to cover material physical (lack of moisture) and/or } \\
\text { chemical (lack of nutrients, salt ingress) properties }\end{array}$ & high \\
\hline 23 & $\begin{array}{l}\text { Poor vegetation establishment due to cover-material physical (lack of moisture) and/or } \\
\text { chemical (lack of nutrients, salt ingress) properties }\end{array}$ & high \\
\hline 24 & $\begin{array}{l}\text { Cracking of top of dump cover leading to venting of lethal gas and accumulation in } \\
\text { enclosures on top of dump }\end{array}$ & critical \\
\hline 25 & Egress of lethal gas from waste storage facility & critical \\
\hline 26 & $\begin{array}{l}\text { Unplanned anthropogenic activity which aids the formation of most of the above failure } \\
\text { modes }\end{array}$ & \\
\hline
\end{tabular}


The second critical risk failure mode was 'freeze/thaw cycles, wet/dry settlement, and development of hummocks leading to cracking of the cover'. This failure mode would result in deterioration of the cover leading to an increase in permeability of the compacted layer of approximately two orders of magnitude. This failure mode had critical severity in the consequence costs category and, combined with an expected likelihood of occurrence $(>50 \%)$, this failure mode became a critical risk failure mode. Mitigation recommendations for this failure mode are:

- inspect landform at regular intervals

- perform routine maintenance to repair cracks.

From a design perspective, this failure mode could be mitigated by ensuring that a change in hydraulic characteristics of cover materials due to frost action is incorporated into the design (i.e. accounted for), rather than result in a reduction in performance relative to expectations.

The third critical risk failure mode was 'vegetation effects on cover performance due to root penetration, blow down, etc'. This failure mode would result in degradation of the compacted layer hydraulic characteristics (e.g. increased permeability, changes to moisture retention characteristics, or increased gas transport). This failure mode had critical severity in the consequence costs category and, combined with a high likelihood of occurrence (10-50\%), this failure mode became a critical risk failure mode. Increasing the thickness of the growth medium layer is an option to mitigate this failure mode.

The fourth critical risk failure mode was 'cracking of top of dump cover leading to venting of lethal gas and accumulation in enclosures on top of dump'. This includes the release of gases with low oxygen concentration due to oxidation reactions inside the dump. This failure mode would result in a space such as a monitoring hut with lethal gas conditions. This failure mode had critical severity in most of the consequence categories (legal and other obligations, consequence costs, community/media/reputation, and human health and safety consequences) and, combined with a high likelihood of occurrence (10-50\%), this failure mode became a critical risk failure mode. Mitigation recommendations for this failure mode are:

- implement institutional controls (e.g. fencing)

- prevent camping

- prevent placement of structures on WR dumps

- install warning signs that dangerous conditions may exist.

The fifth critical risk failure mode was 'egress of lethal gas from waste storage facility'. This failure mode would result in a space with lethal gas conditions. This failure mode had critical severity in most of the consequence categories (legal and other obligations, consequence costs, community/media/reputation, and human health and safety consequences) and, combined with a high likelihood of occurrence (10-50\%), this failure mode became a critical risk failure mode. This failure mode differs from the above failure mode in that there is still potential for an egress of lethal gas even if the cover system has not cracked-other factors may contribute. To mitigate this failure mode, the factors that may contribute to lethal gas accumulation, such as poor air circulation and mixing, need to be evaluated.

\section{Acknowledgement}

The authors acknowledge the contribution of AANDC's Technical Advisory Group (TAG) to the development of the guidance document, from which this paper was based.

\section{References}

Andersland, O.B. and Ladanyi, B. (2004) Frozen Ground Engineering. Hoboken, New Jersey, John Wiley \& Sons, Inc., pp. 363.

Ayres, B., Dobchuk, B., Christensen, D., O'Kane, M. and Fawcett, M. (2006) Incorporation of natural slope features into the design of final landforms for waste rock stockpiles, in Proceedings 7th International Conference for Acid Rock Drainage, 26-30 March, St. Louis, MO, USA, pp. 59-75. 
Carey, S.K. and Woo, M.K. (2001) Spatial variability of hillslope water balance, Wolf Creek basin, subarctic Yukon, Hydrological Processes 15: 3113-3132.

Elshorbagy, A. and Barbour, S.L. (2006) Risk and uncertainty-based assessment of the hydrologic performance of reconstructed watersheds. Paper submitted to ASCE Journal of Geotechnical and Geoenvironmental Engineering (under review).

MEND 1.61.5a (2009) Mine waste covers in cold regions, Mine Environmental Neutral Drainage (MEND) Program, March 2009.

MEND 1.61.5b (2010) Cold regions cover research - Phase 2, Mine Environmental Neutral Drainage (MEND) Program, November 2010.

MEND 2.21.4 (2004) Design, construction and performance monitoring of cover systems for waste rock and tailings, Mine Environmental Neutral Drainage (MEND) Program, July 2004.

MEND 2.21.5 (2007) Macro-scale cover design and performance monitoring reference manual, Mine Environmental Neutral Drainage (MEND) Program, July 2007.

Norman, D.K., Wampler, P.J., Throop, A.H., Schnitzer, E.F., and Roloff, J.M. (1997) Best management practices for reclaiming surface mines in Washington and Oregon. Washington Division of Geology and Earth Resources, Open File Report 96-2, Revised Edition December 1997.

Robertson, A. and Shaw, S. (2006) Mine Closure, InfoMine E-Book, viewed 2 September 2010, http://www.infomine.com/publications/docs/E-Book 02 Mine Closure.pdf.

Washburn, A.L. (1973) Periglacial processes and environments, Edward Arnold Ltd, London, England, 320 p.

Yamazaki, T., Nishida, A. and Kondo, J. (1998) Seasonal frost depth of grounds with the bare surface, snow cover and vegetation, Journal of Japanese Society of Snow and Ice, Vol. 60, pp. 213-224 (in Japanese with English summary).

Zhang, Y., Carey, S.K. and Quinton, W.L. (2008) Evaluation of the algorithms and parameterizations for ground thawing and freezing simulation in permafrost regions, Journal of Geophysical Research, Vol. 113, D17116, doi: 10.1029/2007JD009343. 
